\title{
DOMINANTLY INHERITED DIGITO-TALAR DYSMORPHISM
}

\author{
J. G. Sallis, * Port Elizabeth, and \\ Peter Beighton, $†$ Johannesburg, South Africa
}

Abnormalities of the hands and feet are present in several members of a large Caucasian family resident in Port Elizabeth, South Africa (Fig. 1). The most important features are flexion deformities of the digits, narrowing of the middle phalanges, a single palmar crease,

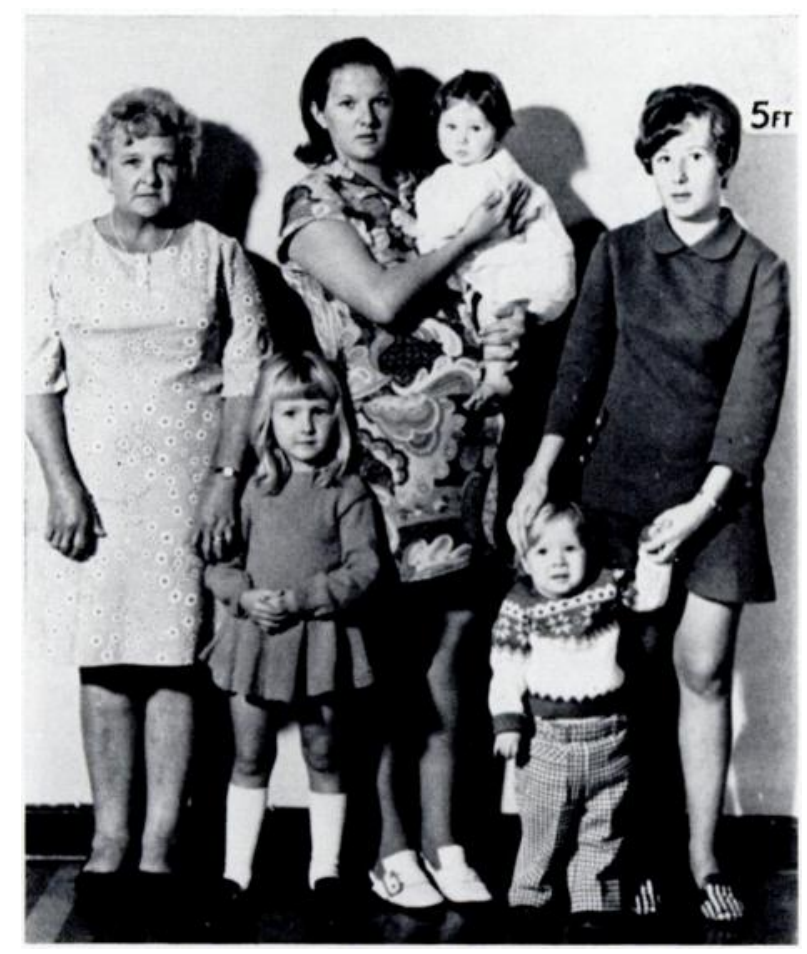

FIG. 1

A group of affected members of the kindred.

and "rocker-bottom" feet due to vertical talus. These abnormalities constitute an inherited syndrome which, to the best of our knowledge, has not been described before. We propose the title digito-talar dysmorphism for this entity. The occurrence of the disorder in fourteen individuals of both sexes, in five generations of the kindred, indicates that the condition is transmitted as an autosomal dominant trait (Fig. 2).

\section{CASE REPORTS}

Case 1-The propositus, patient III-3, was born in 1916. She weighed 59 kilograms (130 pounds) and was 1.5 metres (4 feet 11 inches) in height when she was examined in 1971.

* Orthopaedic surgeon, Port Elizabeth.

† Division of Epidemiology, Department of Orthopaedic Surgery, University of the Witwatersrand, Johannesburg. Present appointment: Professor of Human Genetics, University of Cape Town. 
Deformities of the hands and feet had been apparent at birth, and had neither progressed nor resolved during the course of her life. Operations undertaken in 1966 on each wrist for carpal tunnel syndrome had given complete and lasting relief. Her general health had been good and, apart from a waddling gait, she was little troubled by the condition.

The digits of both hands were fixed in flexion and there was considerable narrowing of the middle phalanges. The skin of the fingers was smooth and shiny, but normal in texture. The palms were also remarkably smooth and only a single transverse palmar crease was present. The forefeet were unusually broad, with severe hallux valgus. The facies was normal and mentality unimpaired. Other systems were all within normal limits. Skeletal survey revealed no abnormality except bilateral vertical talus.

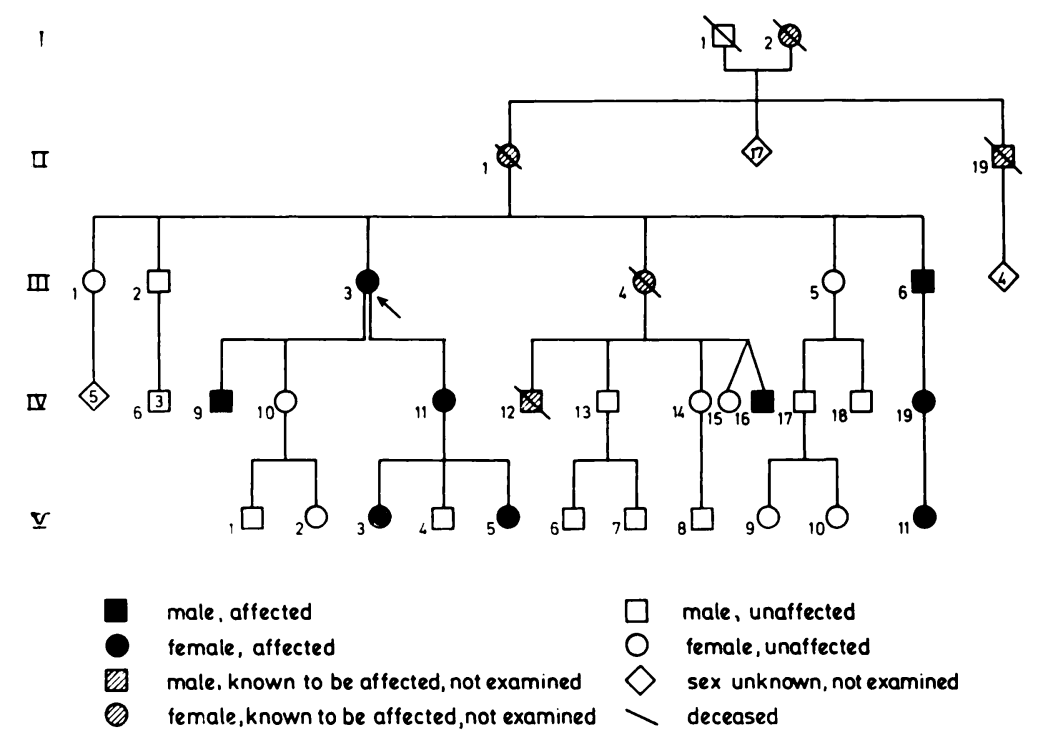

FIG. 2

The pedigree of the kindred, demonstrating typical autosomal dominant inheritance of the trait.

Two of her five siblings had had the disorder and two of her three children were affected, as were her mother and great-grandmother.

Case 2-Patient III-6, the younger brother of the propositus, was born in 1923, with hand deformities like his sister's. Examined in 1971, he was a cheerful cooperative individual, 61.17 kilograms (136 pounds) in weight and 1.6 metres ( 5 feet 4 inches) in height.

He had ulnar deviation and flexion deformities of the fingers. The thumbs were displaced medially and proximally, and movements were limited by a thick soft-tissue web which extended from the proximal phalanx to the palm. The skin of the digits was unusually smooth and shiny and only one transverse palmar crease was present. Narrowing of the middle phalanges was a striking feature. In spite of the severe hand deformities, he was a competent watch repairer. Unlike his sister's, his feet were unaffected. His mentality and all other systems were normal. Skeletal survey revealed no abnormality except slight distortion of the heads of the metacarpals.

His daughter, patient IV-19, had fixed flexion deformities of the fourth and fifth fingers, in the absence of any other abnormality. However, her own infant daughter, patient V-11, had the characteristic deformities of the hands in a severe degree, together with "rocker bottom" feet due to vertical tali. 
Case 3-Patient IV-11, the daughter of patient III-3 by her second husband, was born in 1943. When examined in 1971 she weighed 68 kilograms ( 150 pounds) and was 1.6 metres ( 5 feet 4 inches) in height. There was moderate fixed flexion in the terminal phalanges of both hands, with hyperextension of the proximal phalanges of the fourth and fifth fingers. The fingers narrowed in the region of the middle phalanges, and the digital skin was smooth and shiny. The palms bore a single transverse crease. Her thumbs were malpositioned, but surgical division of the soft-tissue web had permitted improvement in range of movement and function. Her forefeet were broad and flat, and the lateral border of the left foot was convex. Physical examination was otherwise unremarkable, apart from a lower paramedian abdominal scar from a sterilisation operation performed after the birth of her third child.

Her eldest daughter, patient $\mathrm{V}-3$, had had similar hand and foot deformities. Operative release of her left thumb had produced considerable functional improvement. Her son, patient $\mathrm{V}-4$, was clinically normal, but her second daughter, patient $\mathrm{V}-5$, had "rocker-bottom" feet and mild involvement of the hands. Both children had vertical tali.

Case 4-Patient IV-16, the male member of a pair of non-identical twins, was born in 1949 after an uneventful pregnancy and labour. Deformities of his hands and feet were present at birth, although his twin sister was unaffected.

When examined in 1971 he was 1.6 metres ( 5 feet 4 inches) tall, and weighed $66 \cdot 2$ kilograms (146 pounds). His bodily proportions were normal and abnormalities were limited to the hands and feet. He had limitation of all movements of the left wrist, and ulnar deviation of the fingers of the left hand. These fingers had a swan-neck deformity and full extension could only be accomplished after manual correction of a volar subluxation of the metacarpo-phalangeal joints. As distinct from other members of his kindred, these deformities were not fixed, and a full range of passive movements was possible. All the middle phalanges of the left hand had the characteristic narrowing, with apparent paucity of the underlying soft tissues, but the right hand and the thumb of the left hand were normal. The palmar creases resembled those of his affected kindred. The insteps of both feet bulged medially, the lateral borders were unusually convex and the longitudinal arches were lost. He walked with an abnormal gait, the feet being rotated and everted, so that his weight was carried on the medial part of each forefoot. His deformities in no way interfered with his work as an electrician, and he excelled at football

and karate. Radiography demonstrated that the bony structure of the forearms and hands was essentially normal. In the feet, the only significant abnormality was a vertical talus.

His mother and elder brother, who were both deceased, had been affected, but his other siblings and their offspring were normal.

Chromosome investigations in patient IV-16 revealed neither numerical nor structural abnormality.

Other members of the kindred $-\mathrm{A}$ collection of family photographs provided proof that patients I-2, II-1, II-19, III-4 and IV-12, all of whom were deceased, had the characteristic deformities of the hands and feet.

\section{CLINICAL FEATURES}

The following clinical features constitute the digito-talar dysmorphism syndrome. Hands-Ulnar deviation and flexion contractures of the digits, of varying distribution and severity, are a constant feature (Fig. 3). The metacarpo-phalangeal joints may be hyperextended, with flexion of the terminal interphalangeal joints. In some instances, the digits are flexed at all joints. The soft-tissue web may limit movements of the thumb, and the first metacarpal may be situated at an abnormal angle to the carpus, so that the thumb lies in a position of opposition and medial rotation (Fig. 4). Severe deformities of the hands cause surprisingly little disturbance in function, and the unsightly appearances are of greater significance to the patients than any impairment of function (Fig. 5). All affected individuals were unanimous that the deformities neither progressed nor ameliorated with advancing age.

VOL. 54 B, NO. 3, AUGUST 1972 
Abnormal configuration of the soft tissues of the middle phalanges of the fingers produces a narrowing of the digits. However, the underlying phalangeal bones are radiologically normal (Fig. 6). The skin of the fingers is unusually smooth and over the middle phalanges it seems to be tight, giving the appearance of a sleeve drawn over the finger (Fig. 7).

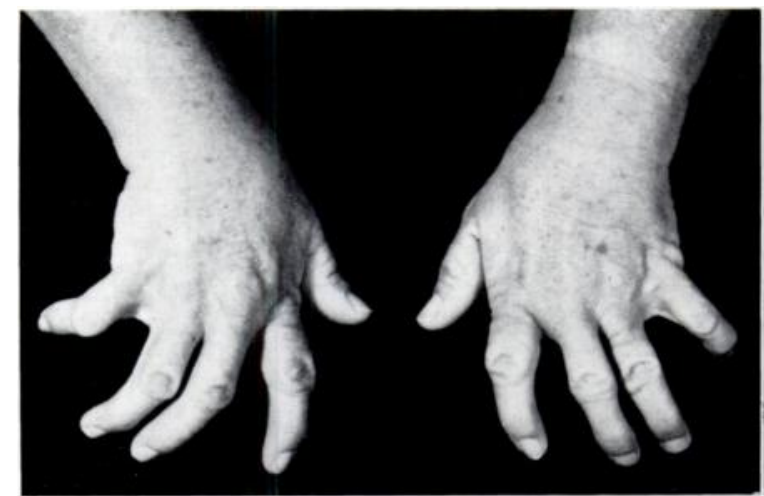

FIG. 3

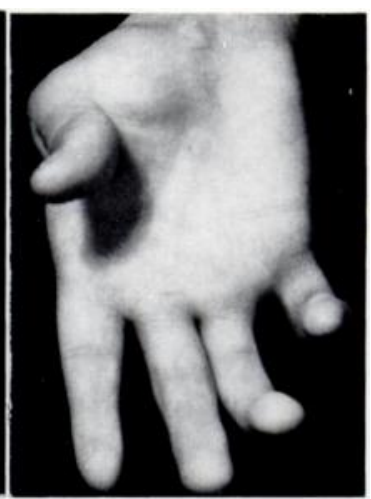

Fig. 4

Figure 3-Patient III-3, the propositus. The digits are fixed in flexion and ulnar deviation. Figure 4-Patient III-6. The thumb is medially rotated and opposed. Movements are limited by a fleshy web.

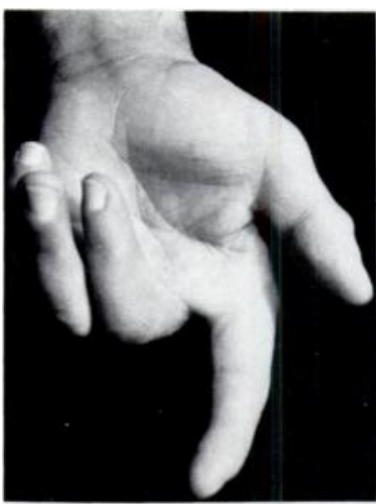

Fig. 5

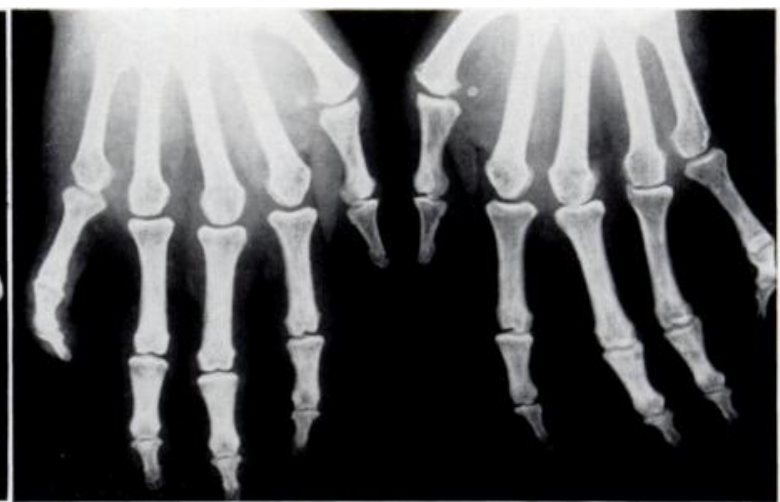

FIG. 6

Figure 5-Patient IV-9. In spite of the unsightly deformity, there is little disturbance in function. This individual was well known for his fine handwriting. Figure 6-Patient IV-11. The narrowing of the middle phalanges is due to soft-tissue changes. The underlying bones are normal. Flexion deformities and ulnar deviation of the digits are clearly seen in this radiograph.

The changes resemble those seen in scleroderma, but in distinction from that condition the skin is soft in texture and in no way bound down to the underlying tissues. There is no evidence of neurological or vascular abnormality in the digits.

Feet-Vertical angulation of the talus produces the characteristic "rocker bottom" deformity of the feet. Other features include increased width of the forefoot and flexion deformities of the toes. Consequently shoe-fitting is difficult and the gait is often disturbed.

Other features-Hair, nails and teeth are normal, as are the cerebrovascular system, respiratory system, central nervous system, genitalia and abdomen. The facies is unremarkable and mentality is unimpaired. Although the affected individuals in the kindred were of relatively short stature, their normal siblings were also short, and it seems evident that abnormal bodily proportions are not a feature of the syndrome. The range of movement in unaffected joints 
is not accentuated. Skeletal survey in patients III-3, IV-9 and IV-11 did not reveal any significant abnormality except the vertical talus.

Dermatogliphics-Affected individuals have a paucity of digital palmar markings, associated with a single transverse crease (the chromosomes were normal).

\section{GENETICS}

The presence of approximately equal numbers of affected and unaffected males and females in five generations of the kindred indicated that the disorder is transmitted as an autosomal dominant trait. It is apparent that the abnormal gene may vary in its clinical expression. For instance, in patient IV-19 the abnormalities were limited to minor flexion deformities of the fourth and fifth fingers (Fig. 8). By contrast, in patients III-3, III-6 and IV-9, there were severe and widespread deformities of the hands and feet. However, the gene was always penetrant. The degree of severity of the deformities was not influenced by the sex of the affected individual.

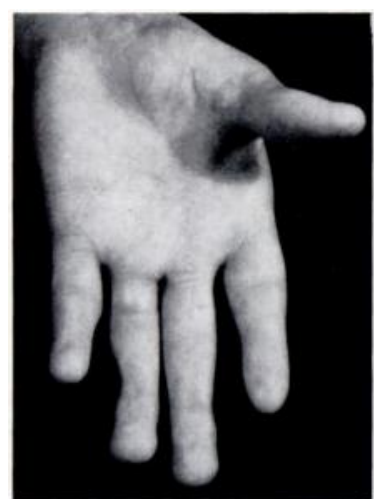

FIG. 7

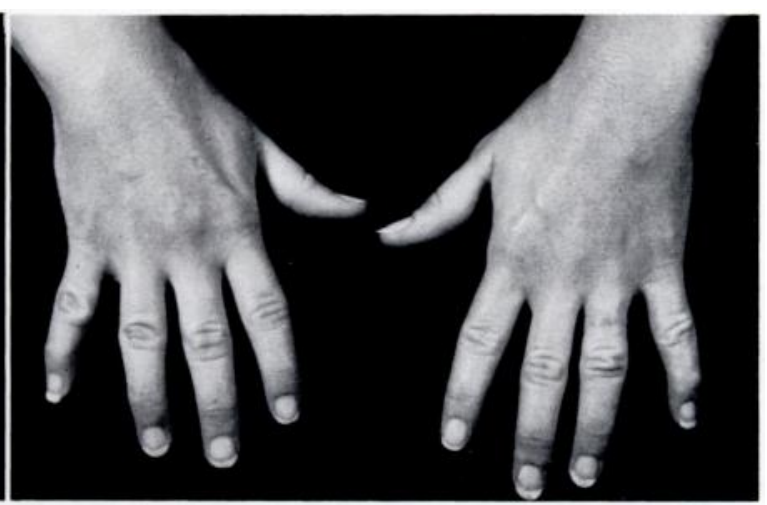

Fig. 8

Figure 7-Patient IV-11. The skin of the fingers is unusually smooth and the middle phalanges are conspicuously narrowed. Division of the soft-tissue web has improved the range of movements of the thumb. Figure 8-Patient IV-19. The gene varied in clinical expression. In this patient, stigmata were limited to minor flexion deformities of the ring and little fingers.

Patients with severe deformities did not have difficulty in obtaining marriage partners. As the life span of affected individuals is normal, genetic fitness to reproduce is probably not reduced.

The single palmar creases were probably a reflection of the underlying anatomical abnormality, but they could have been indicative of a chromosome abnormality. However, the karyotype of patient IV-16 was normal in every respect.

\section{DISCUSSION}

Deformities of the hands and feet are features of a number of genetic or acquired disorders of connective tissue (McKusick 1966, 1968; Smith 1970). However, a careful search of the literature has failed to reveal any previous description of digito-talar dysmorphism.

Digito-talar dysmorphism may be confused with Léri's pleonosteosis (Léri 1922, WatsonJones 1949), but it may be distinguished clinically from that condition by the absence of thickening of the plantar and palmar aponeuroses, and by the fact that there is no anti-mongoloid slant to the eyes. The normality of the facies and intellect distinguishes digito-talar dysmorphism from the various digito-facial syndromes (Papillon-Léage and Psaume 1954; Smith, Lemli and Opitz 1964). The hand changes bear some resemblance to those of rheumatoid arthritis and Dupuytren's contracture, and it is possible that a misdiagnosis of these conditions could be

vol. 54 B, No. 3, AUGUST 1972 
made. Nevertheless, if the family history is positive, the diagnosis of digito-talar dysmorphism is not difficult. The pattern of dominant inheritance and the observation that the deformities in digito-talar dysmorphism are limited to the hands and feet permit differentiation from arthrogryposis multiplex congenita. In two recently published series of patients with this latter condition the abnormalities were usually widespread, and a positive family history was almost always absent (Gibson and Urs 1970, Lloyd-Roberts and Lettin 1970). The syndrome of familial dwarfism and stiff joints described by Moore and Federman (1965) is similar in many respects to digito-talar dysmorphism, but the larger stature and absence of eye complications in digito-talar dysmorphism serve to distinguish the two.

The nature of the basic abnormality is by no means obvious. However, it seems probable that the defect lies in the ligaments and tendons. The hand deformities can be explained, in part, on a basis of an abnormality of the flexor and extensor mechanisms and absence of the lateral portion of the extensor tendon expansions. This abnormality would cause the flexion deformity of the terminal phalanges and the deficiency of soft tissues over the middle phalanges. The fixed deformities which are present in some individuals suggest that the joint capsules may also be involved.

The hand deformities may warrant operation for cosmetic reasons and in some instances considerable functional improvement also can be obtained. Z-plasty has proved to be a useful procedure for the release of the soft-tissue web at the base of the thumb.

Splinting of the hands during infancy may well prevent the flexion deformities from becoming permanently established and early manipulation and stretching of the shortened tissues is often surprisingly rewarding. Improvement in the feet may be obtained by manipulation, plaster-of-Paris correction and open operation. These manoeuvres are primarily directed at the correction of the vertical talus.

It is known that two of the nineteen children of patient I-2 were definitely affected. The remaining seventeen have long since lost touch with the other members of the kindred, but the family believed that many of the offspring of these individuals are living in the Johannesburg area. It is likely, on genetic grounds, that a proportion of these seventeen individuals would have had the condition and it is therefore possible that a considerable number of their descendants would be affected. For this reason digito-talar dysmorphism may well be encountered in the Transvaal.

Nothing is known of the relatives of patient I-2, but as she was an immigrant from Holland, it is possible that there are other affected individuals in that country. Riordan (1971) has treated a mother and her two daughters, who had similar deformities, and who were living in the United States of America. It is not known whether these patients are related to the South African kindred or whether they represent a separate mutation of the same gene.

The recognition of other affected individuals will enhance existing knowledge of the possible range of expression of the abnormal gene. Similarly, evaluation of the results of various methods of treatment will permit the development of the best regime of management.

\section{SUMMARY}

1. A large Caucasian kindred in South Africa are affected by a previously undescribed inherited deformity of the hands and feet called digito-talar dysmorphism.

2. The principal features of digito-talar dysmorphism are flexion deformities, narrowing and ulnar deviation of the fingers. The thumb may be held in an abnormal position by a soft-tissue web. Rocker-bottom foot may develop, due to vertical talus. The facies is normal and the mentality is unimpaired.

3. The general health is good but orthopaedic measures may be needed for function and cosmesis.

4. The condition is transmitted as an autosomal dominant trait, with varying clinical expression of the abnormal gene. 
We are grateful to Professor L. Solomon for his constructive criticism of the manuscript, to Dr C. Wilton for the chromosome investigations and to Mrs G. Beighton for typing the manuscript and drawing the pedigrees.

\section{REFERENCES}

Gibson, D. A., and URS, N. D. K. (1970): Arthrogryposis Multiplex Congenita. Journal of Bone and Joint Surgery, 52-B, 483.

LÉRI, A. (1922): Dystrophie osseuse généralisée, congénitale et héréditaire: la pléonostéose familiale. Presse Médicale, 30, 13.

Lloyd-Roberts, G. C., and Lettin, A. W. F. (1970): Arthrogryposis Multiplex Congenita. Journal of Bone and Joint Surgery, 52-B, 494.

McKusick, V. A. (1966): Heritable Disorders of Connective Tissue. Third edition. St Louis: C. V. Mosby Company.

McKusick, V. A. (1968): Mendelian Inheritance in Man. Second edition. Baltimore: Johns Hopkins Press.

MoOre, W. T., and Federman, D. D. (1965): Familial Dwarfism and "Stiff Joints". Report of a Kindred. Archives of Internal Medicine, 115, 398.

Papillon-Léage, Mme., and Psaume, J. (1954): Une malformation héréditaire de la muqueuse buccale: brides et freins anormaux. Revue de stomatologie, 55, 209.

Riordan, D. (1971): Personal communication.

Sмrтн, D. W. (1970): Recognisable Patterns of Human Malformation: genetic, embryologic, and clinical aspects. Philadelphia: W. B. Saunders \& Co.

Sмith, D. W., Lemli, L., and OpITZ, J. M. (1964): A Newly Recognised Syndrome of Multiple Congenital Anomalies. Journal of Pediatrics, 64, 210.

Watson-Jones, R. (1949): Léri's Pleonosteosis, Carpal Tunnel Compression of the Median Nerves and Morton's Metatarsalgia. Journal of Bone and Joint Surgery, 31-B, 560. 